\title{
System of Measurement
}

National Cancer Institute

\section{Source}

National Cancer Institute. System of Measurement. NCI Thesaurus. Code C70767.

A set of units that can be used to quantitatively specify and characterize entities, objects, phenomena, or events. 